\title{
CEREBRAL BLOOD FLOW AND OXYGEN CONSUMPTION IN HYPERTHYROIDISM BEFORE AND AFTER TREATMENT ${ }^{1}$
}

\author{
By LOUIS SOKOLOFF, RICHARD L. WECHSLER, RENWARD MANGOLD, \\ KENT BALLS, AND SEYMOUR S. KETY
}

\begin{abstract}
(From the Department of Physiology and Pharmacology, Graduate School of Medicine, University of Pennsylvania and the Endocrine Section of the Medical Clinic of the Hospital of the University of Pennsylvania, Philadelphia, Pennsylvania)
\end{abstract}

(Submitted for publication August 22, 1952; accepted December 10, 1952)

It is generally believed that the alterations in total body oxygen consumption which accompany functional disturbances of the thyroid gland reflect widespread metabolic changes in all cells and tissues $(1,2)$. Numerous studies have identified some of the tissues that participate in the over-all disturbance of metabolic rate. For example, in vitro, kidney, liver, heart, and skeletal muscle tissues of animals previously treated with thyroid substance or thyroxine display increased oxygen consumption (3-7), whereas kidney, liver and muscle of thyroidectomized animals show lower than normal oxygen consumptions $(5,8)$. In man, Myers, using the bromsulphalein method, found the splanchnic oxygen consumption in hyperthyroidism to be elevated out of proportion to the total body metabolic rate, although the splanchnic blood flow remained essentially unchanged (9).

In the case of the metabolic rate of the brain, in vitro studies have yielded controversial results. Cohen and Gerard (10) have found considerably higher than normal rates of oxygen consumption in minced brain tissue of rats made hyperthyroid by the administration of thyroid substance. Similar results have been obtained by MacLeod and Reiss (11) who administered thyrotropic hormone following hypophysectomy. On the other hand, no such increases were found by Spirtes (12) or by Gordon and Heming (6), and Fazekas and associates (13) could find no difference from normal in the cortical oxygen consumption of both hyperthyroid and hypothyroid rats.

Studies of the effect of desiccated thyroid substance on the cerebral metabolic rate of human subjects suffering from cretinism were made by Himwich and co-workers (14). Using the thermoelec-

\footnotetext{
1 This investigation was supported in part by a research grant from the Division of Research Grants and Fellowships of the National Institutes of Health, United States Public Health Service.
}

tric flow recorder and cerebral arterio-venous oxygen differences, they found marked increases in cerebral blood flow and cerebral oxygen consumption following thyroid administration. Only relative changes could be measured by this method, however. By means of the nitrous oxide method, quantitative determinations of cerebral blood flow and oxygen consumption in patients with hyperthyroidism have failed to demonstrate any significant differences from normal young men (15-17). On the other hand, in myxedema, a markedly reduced cerebral blood flow and metabolism and an elevated cerebral vascular resistance have been reported by Scheinberg and associates (18). Recently, Madison, Sensenbach and Ochs (19) have reported the results of a similar study on four hyperthyroid and four myxedematous subjects, the latter studied both before and after therapy. Using as normal controls the values obtained when the myxedematous subjects were made euthyroid by treatment, they failed to find in untreated myxedema the decrease in cerebral metabolic rate described by Scheinberg, although the circulatory findings were essentially the same. In their hyperthyroid group, however, in contrast to the previous studies of Sokoloff and his coworkers (15, 16) and Scheinberg (17), Madison and coworkers (19) found the cerebral blood flow to be significantly elevated compared to that in treated myxedema whereas cerebral oxygen consumption was normal.

In view of the discrepancies in the previous studies of cerebral blood flow and metabolism in hyperthyroidism, it was felt that further investigation was indicated. This paper presents the results obtained in a larger group of hyperthyroid patients than previously reported. Repeated studies in the same patients when they were in the euthyroid state following therapy served as controls. This provides not only a more valid basis 
for comparison than that hitherto employed but also provides information on the effect of therapy on the blood flow and metabolism of the brain in hyperthyroidism. Moreover, data on blood $\mathrm{pH}$, carbon dioxide content, carbon dioxide tension, and hemoglobin concentration are presented because of the known effect of these blood constituents on cerebral blood flow (20).

\section{METHOD}

The cerebral blood flow (CBF) of eleven untreated patients with hyperthyroidism, whose ages varied from 21 to 58, was determined by means of the method of Kety and Schmidt (21). The same studies were repeated on seven patients when they were considered to be euthyroid following medical or surgical treatment. Diagnosis was based on clinical history, physical examination, basal metabolic rate, the level of protein-bound iodine in the serum, and in some cases, the rate of $I^{121}$ uptake by the thyroid gland. Mean arterial blood pressure (MABP) was measured with a damped mercury manometer connected to the femoral arterial needle. Blood oxygen and carbon dioxide contents were determined by the manometric method of Van Slyke and Neill (22). Arterial hemoglobin concentration was measured in the Evelyn photometer according to the modification of the method of Evelyn and Malloy (23). Blood $\mathrm{pH}$ was measured anaerobically at room temperature by means of the glass electrode and potentiometer and was corrected to $37^{\circ} \mathrm{C}$., according to the factors of Rosenthal (24). Calculations of the cerebral oxygen consumption $\left(\mathrm{CMR}_{\mathrm{O}_{2}}\right)$, cerebral vascular resistance (CVR), and cerebral respiratory quotient (RQ) were made as described previously (21). Blood carbon dioxide tension $\left(\mathrm{pCO}_{2}\right)$ was computed by means of the nomograms of Peters and Van Slyke (25).

Each patient was in the basal state at the time of the study. Immediately following the procedure for cerebral blood flow determination, the total body metabolic rate was measured with a clinical Benedict-Roth metabolism recording apparatus. The basal metabolic rate determination was performed after the blood flow procedure so as to take into account at least some of the effects of excitement associated with the latter measurement, thus permitting a more valid comparison between cerebral and total body metabolic rates.

\section{RESULTS}

The data are presented in Tables I and II. Included for comparison are the results obtained in 11 normal young men, similarly studied by the same group of investigators over approximately the same period of time. No significant difference from the normal values previously reported by Kety and Schmidt (21) were found in the normal group. Values obtained by Fazekas and his associ- ates (26) in a normal group whose age more closely approximated that of our patients, are also presented in Table I.

In the seven patients studied before and after treatment, the marked fall in basal metabolic rate from +57 per cent to +7 per cent $(p<0.01)$ following therapy was not accompanied by any significant change in $\mathrm{CMR}_{\mathrm{O}_{2}}$. Also, the mean value for $\mathrm{CMR}_{\mathrm{O}_{2}}$ of $3.5 \mathrm{cc} . \mathrm{O}_{2}$ per $100 \mathrm{~g}$. per minute in the untreated group did not differ significantly from that of the normal young men and was identical to the value obtained by Fazekas and his coworkers, in a normal group of comparable age (26). There was no significant correlation between basal metabolic rate and cerebral oxygen consumption in both the treated and untreated groups $(r=-0.06, p>0.1 ; r=-0.18, p>0.1$ respectively). The mean cerebral blood flow of $69.0 \mathrm{cc}$. of blood per $100 \mathrm{~g}$. per minute in untreated hyperthyroidism significantly exceeded the value of 54.2 in Fazekas' group (26) and the value of 54.8 obtained in the normal young men $(p<$ 0.05). Following treatment, cerebral blood flow decreased to $60 \mathrm{cc}$. per $100 \mathrm{~g}$. per minute. This value did not differ significantly from the cerebral blood flow values obtained before therapy, in the normal young men, or in the comparable age group described by Fazekas, Alman, and Bessman (26). The high mean values for mean arterial blood pressure, $104 \mathrm{~mm}$. $\mathrm{Hg}$, agreed closely with the value of $112 \mathrm{~mm}$. $\mathrm{Hg}$ obtained by Fazekas in his group of normal subjects of comparable age (26). On the other hand, the cerebral vascular resistance before treatment was $1.63 \mathrm{~mm}$. $\mathrm{Hg}$ per cc. per 100 g. per minute, a normal value for normal young men but significantly decreased for this age group $(p<0.05)(26)$. This can be attributed to the anemia indicated by the low hemoglobin concentration of $11.35 \mathrm{~g}$. per cent. That cerebral vascular resistance and hemoglobin concentration are interrelated in hyperthyroidism is suggested by the significant correlation between these 2 factors $(r=$ $+0.68 ; \mathrm{p}<0.02)$. Treatment was not accompanied by any significant change in mean arterial blood pressure, cerebral vascular resistance or hemoglobin concentration. Arterial and cerebral venous oxygen contents were significantly lower than normal both before and after treatment $(\mathrm{p}<$ 0.001 ) as a result of the low hemoglobin concentrations. Arterial and cerebral venous $\mathrm{pH}, \mathrm{CO}_{2}$ 

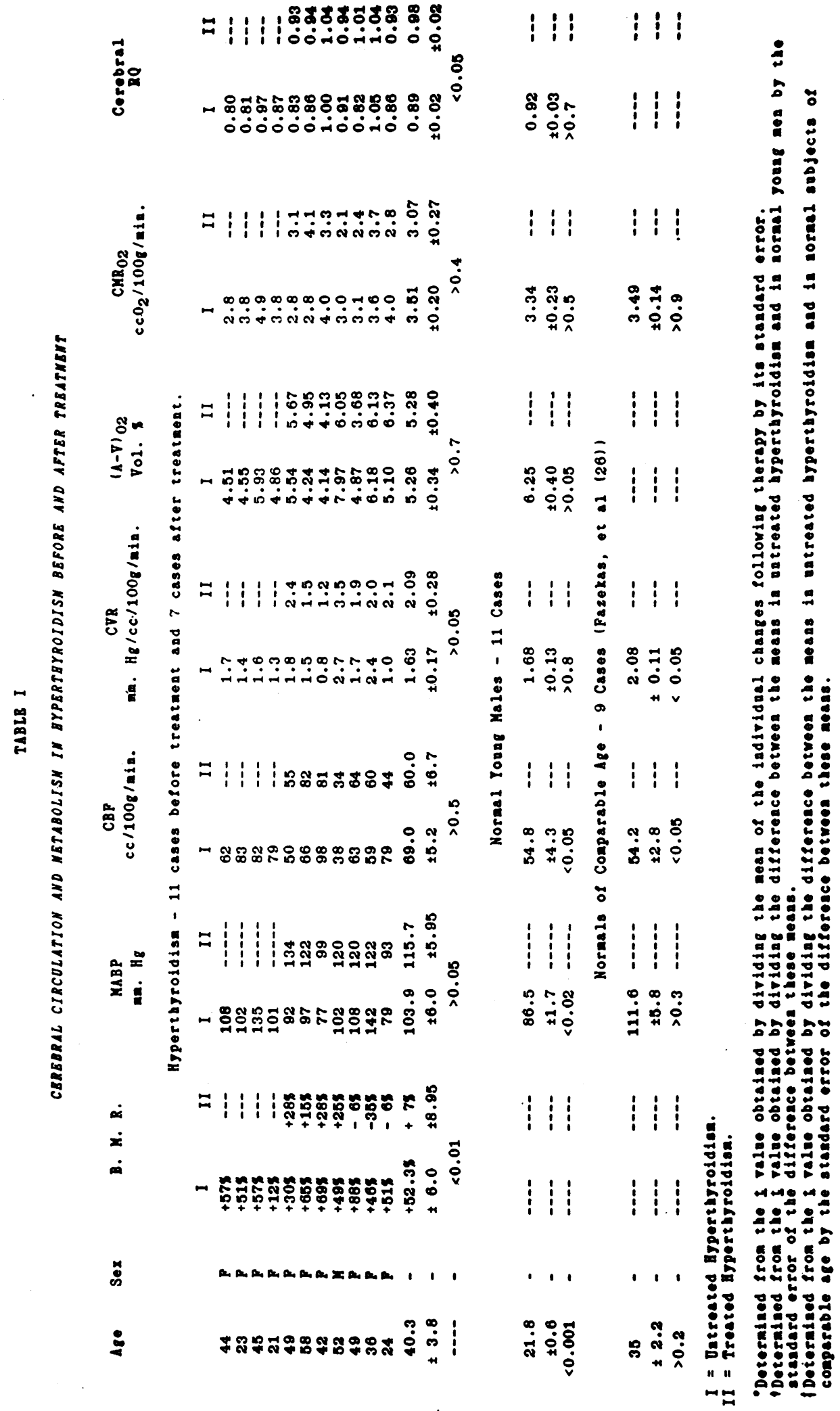

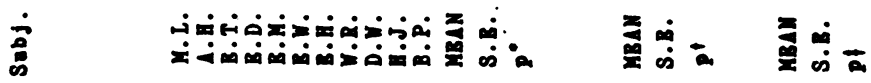




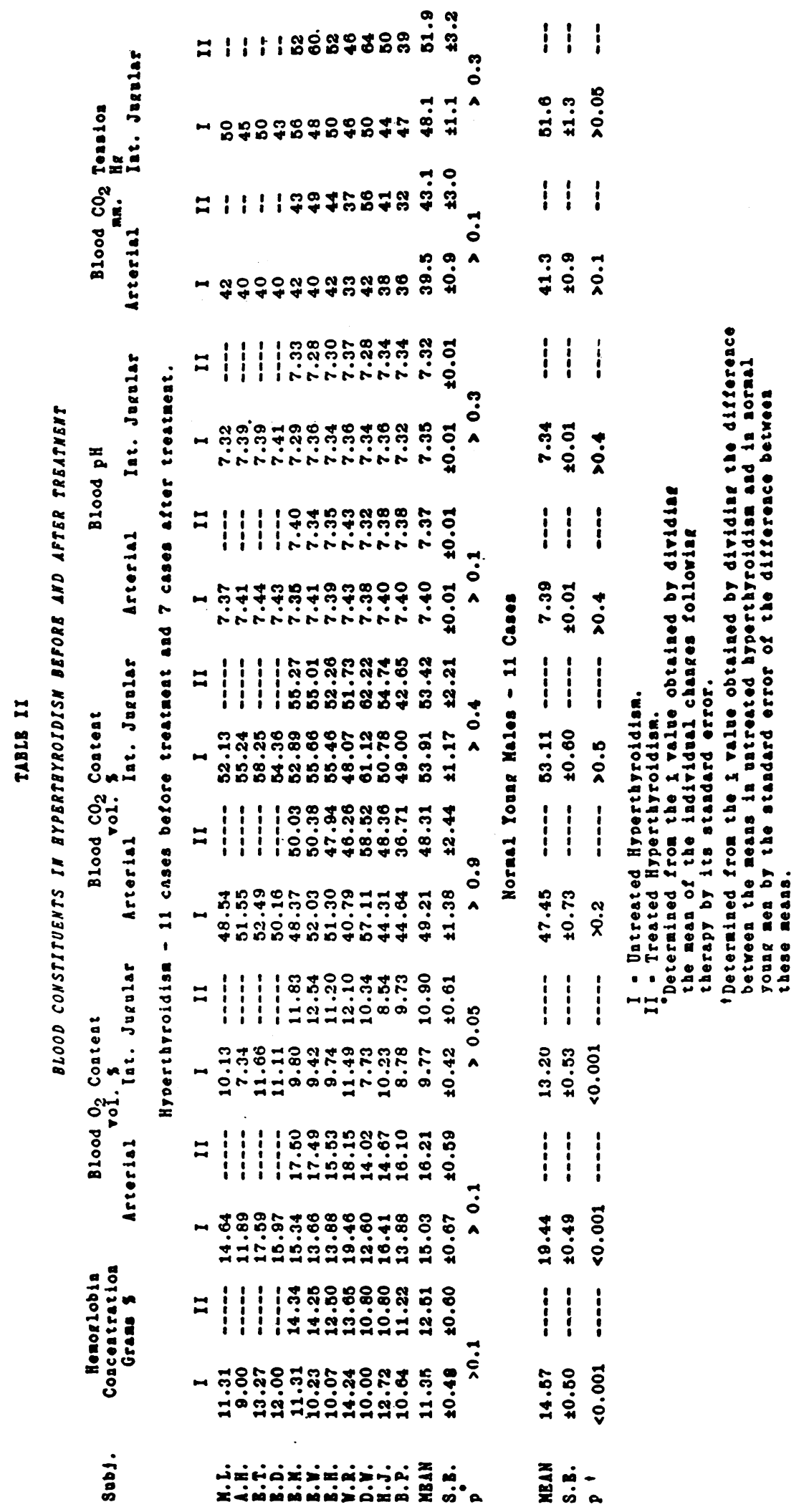


contents, and $\mathrm{CO}_{2}$ tensions were all within normal limits both before and after treatment. Although the values for cerebral respiratory quotient both before and after treatment did not differ significantly from normal, therapy resulted in a significant increase from 0.89 to 0.98 ( $p<0.05)$. The reasons for this change are obscure.

\section{DISCUSSION}

The finding of the same cerebral oxygen consumption in this hyperthyroid group both before and after effective therapy, as well as the lack of a significant difference between this cerebral oxygen consumption and that obtained from a normal group of comparable age and a normal group of young men, certainly suggests that cerebral metabolism is unaltered in hyperthyroidism. This is in agreement with previous observations in this disease $(15-17,19)$. However, cerebral blood flow was found to be significantly elevated in our hyperthyroid group whereas a normal cerebral blood flow was reported by Scheinberg (17). We are unable to explain this discrepancy. In our series, blood $\mathrm{CO}_{2}$ tensions, oxygen saturations and $\mathrm{pH}$, known regulators of cerebral circulation, were found to be normal whereas hemoglobin concentration was significantly reduced. In view of the significant correlation between hemoglobin concentration and cerebral vascular resistance in untreated hyperthyroidism, it appears that the anemia in our patients offers the best explanation for the low cerebral vascular resistance and, consequently, for the elevated cerebral blood flow. In the group studied by Scheinberg, anemia may not have been present, but absence of data on blood constituents precludes further speculation.

The normal cerebral blood flow and $\mathrm{CMR}_{\mathrm{O}_{2}}$ and the greater than normal incidence of a low arterialcerebral venous oxygen difference found by Scheinberg led him to postulate an increased extracerebral contamination of cerebral venous blood in hyperthyroidism (17). If, however, the original nitrous oxide method is employed, independent criteria for the recognition of extra-cerebral contamination are made available (21). Instead of drawing integrated arterial and internal jugular venous blood samples over the full ten minutes, as in Scheinberg's modification, nitrous oxide concentration-time curves for arterial and internal jugular venous blood are constructed on the basis of a number of blood samples taken during the ten minute period. From these curves, the value of $\frac{V_{t} \times 100}{\int_{0}^{t}(A-V) d t}$ from zero time to the end of each minute is calculated. When contamination is absent or insignificant, this function falls rapidly over the first seven minutes and then levels off, and its value over the full ten minutes is taken as the cerebral blood flow. If, on the other hand, the function continues to fall even at ten minutes, then contamination is present, and the rate of fall is an indication of its degree. These criteria apply to contamination with extra-cerebral venous blood, the type most commonly encountered. The remote possibility exists, however, that the contaminating blood may be "arterialized" as, for example, in case of arteriovenous shunts or unusually rapid blood flow through the extra-cerebral tissues. Any contamination of this type sufficient to affect significantly the calculated value obtained for cerebral blood flow would also noticeably alter the internal jugular nitrous oxide concentration-time curve. This curve would then rise more abruptly from zero, and the abrupt rise would be manifest in a disproportionately small integrated arterial-internal jugular nitrous oxide difference over the first minute. On the basis of these criteria, no greater evidence of either type of contamination was found among the hyperthyroid patients than in the treated patients, or normal subjects. It appears, therefore, at least in our group, that the low arterial-cerebral venous oxygen difference in hyperthyroidism is simply the result of an elevated cerebral blood flow in the presence of a normal oxygen consumption.

An explanation of the failure of the brain to participate in the increased total body metabolism in hyperthyroidism can at the present time be only speculative. Cerebral metabolism may be unaffected by the thyroid hormone because of an inability of the active principle to penetrate the blood-brain barrier. We are unaware, however, of any information concerning this problem.

Scheinberg (17), supported by Fazekas (13), has postulated that the "cerebral metabolism normally functions at close to its maximum rate and that a large part of the energy used by the brain goes to maintaining the structural and biochemical 
organization of the brain." Supposedly, therefore, hyperthyroidism could not be expected to cause a measurable increase in cerebral oxygen consumption above the normal level. This hypothesis is questionable, in view of the recent observations of significantly elevated cerebral metabolic rates in response to infusions of synthetic 1-epinephrine (27) and in moderate muscular exercise (28).

A more likely explanation for the normal oxygen consumption of the brain in hyperthyroidism is simply that the energy metabolism of the fully developed brain is of such a nature as to render it independent of the action of the thyroid hormone. The uniqueness of the cerebral metabolism is already indicated in the fact that the normal brain derives its energy almost exclusively from the utilization of carbohydrate $(29,30)$. Similarly, the testis, which is also believed to utilize only carbohydrate (31), has a normal oxygen consumption in hyperthyroidism (6). It appears then that the thyroid hormone, whose exact function in intermediary metabolism is still unknown, does not measurably alter the metabolic processes of those tissues which consume carbohydrate for energy almost exclusively. On the other hand, Fazekas (13) has observed that in brain tissue in which protein metabolism must be significant (e.g., the developing rat cortex), the oxygen consumption rises more rapidly to the normal adult level in induced hyperthyroidism than in the normal or hypothyroid states. Once fully developed to the adult level, however, when growth and protein metabolism become less significant, the oxygen consumption was found to be the same in the normal, hypothyroid and hyperthyroid groups (13). Since the thyroid hormone does influence the development of the brain (13), i.e., its structural and enzymatic proteins, it is likely that it is also involved in the maintenance of these systems in the mature brain. This effect in the mature brain, however, may be normally not detectable because of the low turn-over rate of these protein systems compared to that of the carbohydrates. When the thyroid hormone is insufficient adequately to maintain these systems, as, for example, in myxedema, then secondarily, the energy producing carbohydrate metabolism may be impaired and this reflected in a lowered cerebral oxygen consumption $(14,18)$.

\section{SUMMARY}

1. Studies of cerebral blood flow, cerebral vascular resistance, and cerebral oxygen consumption, as well as mean arterial blood pressure, hemoglobin concentration, blood gases, and blood $\mathrm{pH}$, were made on eleven untreated hyperthyroid patients and then repeated on seven following treatment.

2. Cerebral oxygen consumption was entirely normal and was not significantly correlated with basal metabolic rate.

3. Comparison with the results of similar studies in normal individuals indicated a moderate elevation of cerebral blood flow in untreated hyperthyroidism probably because of an associated anemia. Mean arterial blood pressure was normal, but cerebral vascular resistance was low for this age group. Except for the low oxygen contents associated with a moderate anemia, blood gases were found to be within normal limits.

4. Treatment did not result in any significant changes except for the decrease of the basal metabolic rate to the normal level and an increase in the cerebral respiratory quotient.

5. Possible explanations for the failure of the brain to participate in the elevated total body metabolic rate are discussed. It is suggested that the gross energy metabolism of the brain, as reflected by the oxygen utilization, may be independent of the action of the thyroid hormone.

\section{ACKNOWLEDGMENTS}

The authors wish to express their appreciation to Dr. J. H. Comroe, Jr., Dr. E. Rose and Dr. B. D. Polis for valuable suggestions and to Miss Hilda Klotz, Miss Grace Mellwig and Miss Carolyn Doernbach for their technical assistance.

\section{REFERENCES}

1 Means, J. H., The Function of the Thyroid Gland. Springfield, Ill., Charles C. Thomas, 1949.

2. Peters, J. P., and Van Slyke, D. D., Quantitative Clinical Chemistry. Vol. I, Interpretation. Baltimore, Williams and Wilkins, 1946, 2nd edition, p. 49.

3. Asher, L., Beitrage zur Physiologie der Drüsen, Nr. 61. Rohrer, A., Vergleich des Sauerstoff verbrauchs Uberlebender Säugetierorgane im normalen Zustande und nach Fütterung mit Schilddrüsenhormon. Biochem. Ztschr., 1924, 145, 154. 
4. McEachern, D., The metabolism of isolated surviving tissues from animals rendered hyperthyroid with thyroxine. Bull. Johns Hopkins Hospital, 1935, 56, 145.

5. Rapport, D., Canzanelli, A., and Guild, R., The effect of thyroidectomy on the tissue response to administered thyroxin. Endocrinology, 1946, 38, 260.

6. Gordon, E. S., and Heming, A. E., The effect of thyroid treatment on the respiration of various rat tissues. Endocrinology, 1944, 34, 353.

7. Andrus, E. C., The heart in hyperthyroidism : a clinical and experimental study. Am. Heart J., 1932, 8, 66.

8. Foster, G. L., A note on tissue respiration in relation to thyroidectomy. Proc. Soc. Exper. Biol. \& Med., 1927, 24, 334.

9. Myers, J. D., Brannon, E. S., and Holland, B. C., A correlative study of the cardiac output and the hepatic circulation in hyperthyroidism. J. Clin. Invest., 1950, 29, 1069.

10. Cohen, R. A., and Gerard, R. W., Hyperthyroidism and brain oxidations. J. Cell. \& Comp. Physiol., 1937, 10, 223.

11. MacLeod, L. D., and Reiss, M., Tissue metabolism of brain cortex and liver after hypophysectomy and treatment with thyrotrophic hormone. Biochem. J., 1940, 34, 820.

12. Spirtes, M. A., Oxygen consumption of brain cortex in thyrotoxic guinea pigs. Proc. Soc. Exper. Biol. \& Med., 1941, 46, 279.

13. Fazekas, J. F., Graves, F. B., and Alman, R. W., The influence of the thyroid on cerebral metabolism. Endocrinology, 1951, 48, 169.

14. Himwich, H. E., Daly, C., Fazekas, J. F., and Herrlich, H. C., Effect of thyroid medication on brain metabolism of cretins. Am. J. Psychiat., 1942, 98, 489.

15. Sokoloff, L., Wechsler, R. L., Balls, K., Mangold, R., and Kety, S. S., The blood flow and $\mathrm{O}_{2}$ consumption of the human brain in hyperthyroidism. Am. J. M. Sc., 1950, 219, 465.

16. Sokoloff, L., Wechsler, R. L., Balls, K., and Kety, S., The relation of the cerebral $\mathrm{O}_{2}$ consumption to the total body metabolism in hyperthyroidism. J. Clin. Invest., 1950, 29, 847.

17. Scheinberg, P., Cerebral circulation and metabolism in hyperthyroidism. J. Clin. Invest., 1950, 29, 1010.
18. Scheinberg, P., Stead, E. A., Jr., Brannon, E. S., and Warren, J. V., Correlative observations on cerebral metabolism and cardiac output in myxedema. J. Clin. Invest., 1950, 29, 1139.

19. Madison, L., Sensenbach, W., and Ochs, L., Effect of hyperthyroidism and myxedema upon cerebral blood flow and metabolism. Am. J. Med., 1951, 11, 246.

20. Kety, S. S., Circulation and metabolism of the human brain in health and disease. Am. J. Med., 1950, 8, 205.

21. Kety, S. S., and Schmidt, C. F., The nitrous oxide method for the quantitative determination of cerebral blood flow in man : theory, procedure and normal values. J. Clin. Invest., 1948, 27, 476.

22. Van Slyke, D. D., and Neill, J. M., The determination of gases in blood and other solutions by vacuum extraction and manometric measurement. I. J. Biol. Chem., 1924, 61, 523.

23. Evelyn, K. A., and Malloy, H. T., Microdetermination of oxyhemoglobin, methemoglobin, and sulfhemoglobin in a single sample of blood. J. Biol. Chem., 1938, 126, 655.

24. Rosenthal, T. B., The effect of temperature on $\mathrm{pH}$ of blood and plasma in vitro. J. Biol. Chem., 1948, 173, 25.

25. Peters, J. P., and Van Slyke, D. D., Quantitative Clinical Chemistry. Baltimore, Williams and Wilkins, 1931-32.

26. Fazekas, J. F., Alman, R. W., and Bessman, A. N., Cerebral physiology of the aged. Am. J. M. Sc., 1952, 223, 245.

27. King, B. D., Sokoloff, L., and Wechsler, R. L., The effects of 1-epinephrine and 1-nor-epinephrine upon cerebral circulation and metabolism in man. $\mathrm{J}$. Clin. Invest., 1952, 31, 273.

28. Kleinerman, J. I., To be published.

29. Himwich, H. E., and Nahum, L. H., The respiratory quotient of the brain. Am. J. Physiol., 1932, 101, 446.

30. Kety, S. S., Woodford, R. B., Harmel, M. H., Freyhan, F. A., Appel, K. E., and Schmidt, C. F., Cerebral blood flow and metabolism in schizophrenia. The effects of barbiturate semi-narcosis, insulin coma, and electroshock. Am. J. Psychiat., 1948, 104, 765.

31. Himwich, H. E., and Nahum, L. H., The respiratory quotient of testicle. Am. J. Physiol., 1929, 88, 680. 